DOI: $10.14451 / 1.186 .145$

\title{
СФЕРА СТРОИТЕЛЬСТВА В СИСТЕМЕ ЭКОНОМИЧЕСКИХ ВЗАИМООТНОШЕНИЙ РОССИИ И КИТАЯ
}

\section{(C) 2020 Юй Цзинчэнь}

аспирант, кафедра экономики и управления предприятиями и производственными комплексами Санкт-Петербургский государственный экономический университет, Россия, Санкт-Петербург

E-mail: may_9171@mail.ru

В статье рассматриваются вопросы взаимодействия России и Китая в сфере строительства. Показана эволюция вхождения Китая в строительную сферу России. На основе ряда примеров показано, что вектор взаимодействия стран в строительстве смещается в сторону сотрудничества в высокотехнологичных сферах, в частности, в строительстве метро.

Ключевые слова: строительство, Россия, Китай, сотрудничество

Взаимодействие России и Китая имеет свою давнюю политическую и экономическую историю, которая знала и времена противостояния и тесного сотрудничества. Действительно, экономические отношения развивались достаточно интенсивно, однако определенное ускорение было получено в период после начала действия санкций против России в 2014 году под предлогом «аннексии» Крыма. На рис.1 показана динамика товарооборота между Россией, Китаем и ЕС в 2010-2019 гг. [1]

При этом доля Китая в товарообороте РФ выросла с $12,1 \%$ в 2010 году до $15,7 \%$ в 2019 году, в то время как доля ЕС сократилась с $48,2 \%$ до $41,7 \%$. Все эти годы Китай стабильно занимает первое место в российском экспорте, хотя сама структура экспорта показывает акцент на поставку продукции нефтегазового комплекса, неметаллических и металлических руд, древесины, т.е. практически непереработанного сырья. Тем не менее, как видно из приведенных данных диверсификации экспорта достичь не удалось. Все это явилось результатом определенной переориентации экономической политики на Восток с целью компенсации потерь, возникших в результате санкций.

Современное состояние взаимодействия китайских строительных корпораций с российской стороной требует, в первую очередь, характеристики, которыми можно обозначить их место в мировом экономическом пространстве. По данным журнала Fortune [2] среди китайских наиболее значимых корпораций, занимающих место в топ-500 в настоящее время входят три строительные корпорации. Российский строительный рынок, уже начиная с 2005-2006 годов является достаточно привлекательным для китайских корпораций по ряду причин, причем генезис

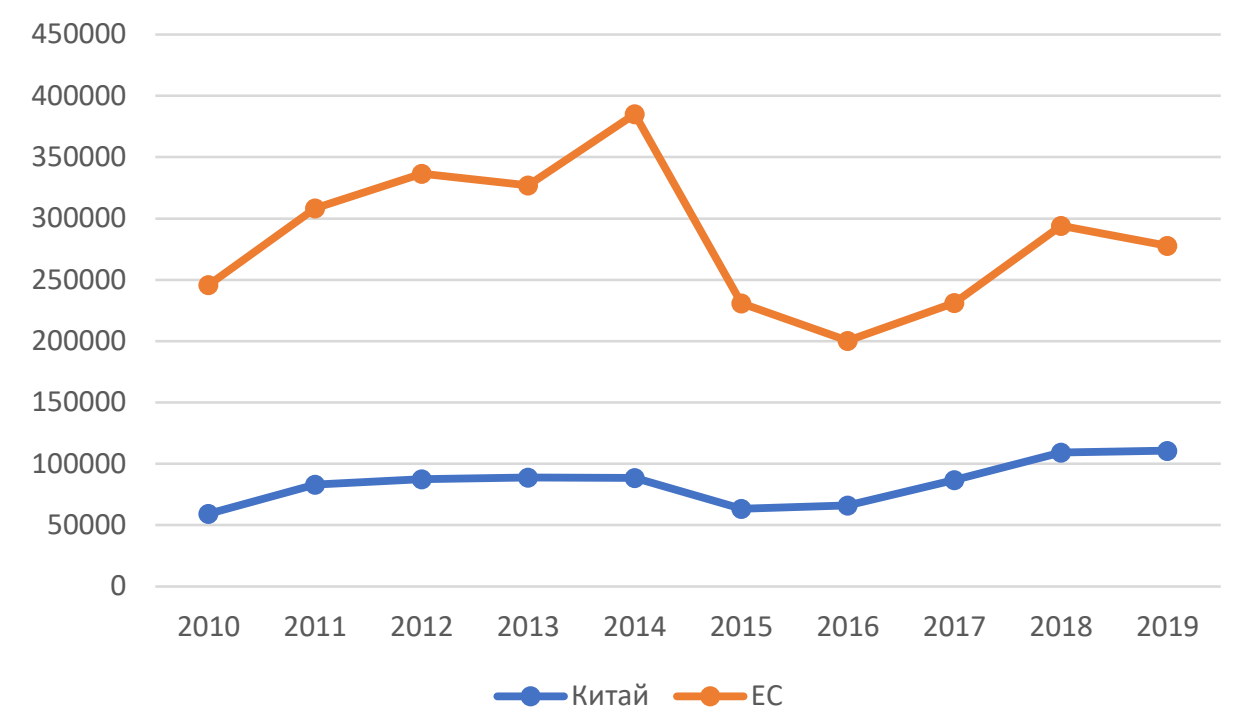

Puc. 1. Динамика товарооборота России с Китаем и ЕС, млрд.долл 
этого интереса зависит от стадии проникновения китайского строительного бизнеса. Так, первый этап характеризовался тем, что в России появились три группы акторов, участвующих в строительном процессе, а именно, китайские строительные рабочие, китайские подрядчики и китайские застройщики. При этом к каждой из этих групп в России сложилось неоднозначное отношение, причем изменяющееся во времени. В начальный период, появление китайских строителей на рынке рабочей силы в строительстве только приветствовалось (высокое качество выполняемых работ, возможность сравнительно низкой оплаты труда по сравнению с российским контингентом; статус китайской рабочей силы, в основном являвшихся нелегальными мигрантами). Еще в 2007 году отмечалось, что по данным ФМС, на один миллион официально зарегистрированных трудовых мигрантов на КНР приходилось примерно 210 тысяч человек [3]. При этом в ряде публикаций и исследований (в основном китайских авторов) отмечалось [4], что «Отказаться полностью от рабочей силы из КНР Россия не сможет, да и для ее экономики это не будет выгодным». В то же время нарастал негативный эффект привлечения строителей из Китая, который выражался в снижении доли российских граждан в структуре рабочей силы в строительстве, хотя, как признавалось, в строительстве в основном были трудоустроены мигранты из Турции. К сожалению, данные именно по строительной отрасли отсутствуют, однако анализируя отдельные показатели миграционной ситуации в Российской Федерации за период сентябрь-июнь 2019 года [5], можно сказать, что по количеству фактов постановки на миграционный учет с целью работы Китай занимает лишь седьмое место после ряда государств бывших республик СССР.

В современных условиях считается, что полностью или в большей своей части заменить российских строителей китайскими навряд ли возможно не смогут, но они могут составить серьезную конкуренцию именно в части высокотехнологичных строительных профессий, связанных в основном со строительством объектов по мегапроектам и, соответственно, повлиять на этот сегмент рынка.

Что касается появления на российском строительном рынке китайских подрядчиков и субподрядчиков из Китая, то надо отметить, что российские строительные компании в свое вре- мя достаточно часто использовали их услуги, что объяснялось определенной институализацией процесса, поскольку работать со строительной организацией гораздо проще, чем с отдельными рабочими. Привлекало и то, что проблемы, связанные с юридическим оформлением строительных рабочих, бралась решать китайская сторона.

Если говорить о крупных китайских корпорациях из списка Fortune, то в первую очередь надо сказать о China State Construction Engineering, которая присутствует в России с 2005 года, реализуя наиболее крупные инвестиционные проекты, к числу которых можно отнести бизнес-центр «Парк Хуамин», «Москва Сити» и ряд других ЕРС-контрактов в России. China Railway Constructionтакже достаточно интенсивно вовлечена в крупные российские проекты, к которым можно было бы отнести строительство части «Большого кольца» московского метро, в том числе станций «Проспект Вернадского», «Аминьевское шоссе» и «Мичуринский проспект».

Еще один аспект взаимодействия российских и китайских компаний в сфере строительства связан непосредственно не только с процессом строительства как такового, но и с его инфраструктурой, в частности с производством строительного оборудования. Нужно отметить, что если еще недавно, практически все оборудование для строительства импортировалось в Россию из Европы и Японии (Caterpillar, Komatsu, Hitachi, Liebherr и др.) то в настоящее время произошло некоторое смещение акцентов на китайскую строительную технику, широкий спектр которой уже поставляется во многие страны мира: скреперы, бульдозеры, трубоукладчики, башенные краны, бетономешалки и др. Так, в рейтинге производителей строительной техники китайская компания XCMG занимает в настоящее время 10-е место, успешно конкурируя и сотрудничая с ведущими мировыми производителями.

Особо стоит отметить используемые в настоящее время при прокладке метро в Москве проходческие щиты. В 2018 году в Россию был экспортирован первый проходческий щит, произведенный China Railway Construction Heavy Industry Group, первая из пяти машин, самостоятельно разработанных Китаем для работы в холодном климате России. Второй щит «Мария» был специально модифицирован для соответ- 
ствующего климата и конкретной геологической ситуации, в частности для работы при -20 С.

Следует отметить, что развитие сотрудничества России и Китая в сфере строительства, в частности прокладки линий метро и строительства станций, не является чем-то сюиминутным. Так, в конце 2019 года было подписано соглашение о стратегическом партнерстве между AO «Метрогипротранс» и «Shanxi Construction Investment Group Co., LTD» (SCIG) и, более того, было принято решение о создании совместной «Европейско-Азиатской инвестиционностроительной корпорации» (ЕАИСК), задачей которой является реализация крупных частногосударственных проектов.

В продолжение развития сотрудничества и учитывая позитивный опыт Москвы во взаимодействии с корпорацией SCIG, а также не самую лучшую ситуацию, которая сложилась вокруг строительства метрополитена в СанктПетербург, возникло решение о создании проектно-строительного консорциума, в со- став которого, как предполагается, могут войти упоминавшаяся выше Европейско-Азиатская инвестиционно-строительная корпорация, АО «Метрострой» - в качестве строительной организации, АО «Метрогипротранс» - в качестве проектного института, а также SCIG - в качестве инвестиционной компании для интенсификации строительства метро в Санкт-Петербурге. Интерес китайской стороны к этому проекту проявлялся и раньше. В свое время в ходе обсуждения возникших у Метростроя проблем, в качестве потенциальных подрядчиков уже упоминались в частности, «Стройтрансгаз», «Мостотрест», «Трансинжстрой», а также китайские компании.

Таким образом можно сделать вывод, что в современных условиях вектор взаимодействия России и Китая в строительстве смещается от жилищного строительства (хотя и не исключает его) в сторону высокотехнологичных видов строительной деятельности.

\section{Библиографический список}

1. Динамика торговли России с Китаем. https://russian-trade.com/reports-and-reviews/2018-03/dinamikatorgovli-rossii-s-kitaem-v-2010-2017-godah/; Коростиков М. Дружба на расстоянии руки. https://www. kommersant.ru/doc/3984186

2. https://fortune.com/global500/2018/

3. Великая гастарбайтерская стена. https://lenta.ru/articles/2007/06/05/migrant/

4. Ян Хунмэй. Китайская миграция в Россию: тенденции, последствия и подходы к регулированию.-Автореф. дисс.канд.экон.наук.-М.:2008.

5. Отдельные показатели миграционной ситуации в Российской Федерации за январь - сентябрь 2019 года с распределением по странам и регионам. https://мвд.pф/Deljatelnost/statistics/migracionnaya/item/18630986/ 